coefficients of ESR with the other laboratory parameters. ESR correlated moderately with CRP amongst all groups $(r=0.47-0.58)$; weakly with ferritin in the general and the flare group $(r=0.26)$; and very weakly with C3-reduction and raised dsDNA-antibodies $(r<0.2)$ in each group. Concerning proteinuria, the correlation was weak for all, for flaring and for silent patients $(r=0.22-0.35)$, moderate for patients with both infection and activity $(r=0.56)$. There was no correlation in infected patients $(r<0.06)$. Table 1 (bottom part) displays the $p$-values for the association of parameters with disease activity or infection, respectively. ESR, reduction of $\mathrm{C} 3$, proteinuria and raised dsDNA-antibodies were all associated with disease activity in the whole cohort and in the non-infected group; CRP only in non-infected patients. In the infected group, raised dsDNA-antibodies and proteinuria were the only parameters showing significant relation to disease activity. ESR and CRP were significantly associated with infections when looking at all or at inactive patients, but not in active patients.

Table 1: Correlation of laboratory parameters to ESR and association with disease flare and infection

\begin{tabular}{|c|c|c|c|c|c|c|}
\hline Parameters & ESR & CRP & Ferritin & \begin{tabular}{|l|} 
C3- \\
reduction
\end{tabular} & $\begin{array}{l}\text { Raised dsDNA- } \\
\text { antihodies }\end{array}$ & Proteinuria \\
\hline \multicolumn{7}{|c|}{ Coefficients for correlation to ESR } \\
\hline $\begin{array}{l}\text { all patients } \\
(\mathrm{n}=371)\end{array}$ & & $0.498^{*}$ & $0.256^{*}$ & $0.165^{*}$ & $0.134^{*}$ & $0.349^{*}$ \\
\hline $\begin{array}{l}\text { flare only } \\
(n=147)\end{array}$ & & $0.549 *$ & $0.268^{*}$ & 0.064 & 0.101 & $0.222^{*}$ \\
\hline $\begin{array}{l}\text { Infection only } \\
(n=48)\end{array}$ & & $0.468 *$ & 0.109 & 0.172 & 0.12 & 0.056 \\
\hline $\begin{array}{l}\text { both } \\
(n=23)\end{array}$ & & $0.575^{*}$ & 0.266 & 0.037 & 0.205 & $0.556^{*}$ \\
\hline $\begin{array}{l}\text { silent } \\
(\mathrm{n}=153)\end{array}$ & & $0.556^{*}$ & 0.25 & 0.032 & 0.082 & $0.341^{*}$ \\
\hline \multicolumn{7}{|c|}{ P-value for the association with disease activity } \\
\hline $\begin{array}{l}\text { all patients } \\
(\mathrm{n}=371)\end{array}$ & \begin{tabular}{|l|}
$<0.001$ \\
$*$
\end{tabular} & 0.692 & 0.405 & $<0.001^{*}$ & $<0.001^{*}$ & $<0.001^{*}$ \\
\hline $\begin{array}{l}\text { without infection } \\
(n=300)\end{array}$ & $<0.001^{*}$ & $<0.001 *$ & 0.318 & $<0.001^{*}$ & $<0.001^{*}$ & $<0.001^{*}$ \\
\hline $\begin{array}{l}\text { with infection } \\
(\mathrm{n}=71)\end{array}$ & 0.186 & 0.321 & 0.713 & 0.268 & $<0.001^{*}$ & $0.007^{*}$ \\
\hline \multicolumn{7}{|c|}{ P-value for the association with infections } \\
\hline $\begin{array}{l}\text { all patients } \\
(\mathrm{n}=371)\end{array}$ & $<0.001^{*}$ & $<0.001^{*}$ & 0.797 & 0.384 & $0.023^{*}$ & 0.059 \\
\hline $\begin{array}{l}\text { without activity } \\
(\mathrm{n}=201)\end{array}$ & $<0.001^{*}$ & $<0.001^{*}$ & 0.642 & 0.281 & 0.068 & 0.088 \\
\hline $\begin{array}{l}\text { with activity } \\
(\mathrm{n}=170)\end{array}$ & 0.039 & 0.213 & 0.576 & 0.255 & 1 & 0.057 \\
\hline
\end{tabular}

Conclusions: Both, ESR and CRP are elevated in patients with SLE flare and are weakly correlated with other laboratory activity parameters. Thus, while normal CRP argues against infection elevation of ESR and CRP is not sufficient to distinguish between SLE flare and infection.

Disclosure of Interest: None declared

DOI: 10.1136/annrheumdis-2017-eular.5123

\section{AB0540 ORGAN DAMAGE IN PATIENTS WITH SYSTEMIC LUPUS ERYTHEMATOSUS}

V. Zivkovic ${ }^{1}$, B. Mitic ${ }^{2}$, B. Stamenkovic ${ }^{1}$, S. Milenkovic ${ }^{1}$, J. Jovanovic ${ }^{1}$ I. Aleksic ${ }^{1} .{ }^{1}$ Institute for Treatment and Rehabilitation "Niška Banja", Niska Banja; ${ }^{2}$ Clinic of nephrology Clinical centre Nis, Nis, Serbia

Background: Organ damage in patients with systemic lupus erythematosus (SLE) occurs as the consequence of the disease itself, administered therapy, primarily corticosteroid and cytostatic, as well as the accompanying diseases and complications.

Objectives: Our aim in this paper was to examine the degree of irreversible organ changes in SLE patients using the SLICC/ACR Damage Index (SDI) and to establish the correlation of organ damage with disease activity, quality of life, and severity of fatigue, as well as with the immunological parameters - anti-dsDNA antibodies, anti-nucleosome, anti-C1q antibodies, and MCP1 in the serum and urine.

Methods: The study involved 83 SLE patients (77 women and 6 men), aged $45.8 \pm 9.2$ years on the average, with average disease duration of $10.6 \pm 7.9$ years, hospitalized at the Clinic of Rheumatology of the "Niška Banja" Institute, in whom the diagnosis was made based on the revised 1997 ACR criteria. The disease activity was evaluated using the Systemic Lupus Erythematosus Disease Activity Index (SLEDAl) and a physician's global assessment. The degree of organ damage was evaluated using the SDI. The quality of life was assessed based on The Medical Outcome Survey Short Form 36 (SF-36), and the severity of fatigue was measured using the Fatique Severity Scale (FSS). The level of antibodies was determined using the ELISA test, and serum and urine MCP1 with the sandwich enzyme immunosorbent assay method according to the manufacturer's instructions (R\&D Systems, Inc. Minneapolis, USA).

Results: The mean value of organ damage index in all SLE patients was 1.8 \pm 2.0 (median $1, \min 0, \max 9)$. Twenty-five $(30.1 \%)$ patients did not have any organ damage $(\mathrm{SDI}=0) ; 21(25.3 \%)$ had $\mathrm{SDI}=1 ; \mathrm{SDI}=2$ or 3 was found in 20 patients $(24.1 \%)$, and 17 patients $(20.5 \%)$ had $\mathrm{SDI} \geq 4$. Neuropsychic and musculoskeletal changes were the most common organ damage manifestations, present in 23
(27.7\%) of patients. In 21 patients $(25.3 \%)$, cardiovascular changes were seen, and ocular lesions in 14 patients $(16.9 \%)$. Renal and pulmonary changes were found in 13 patients $(15.7 \%)$, cutaneous changes in 3 patients $(3.6 \%)$, and gastrointestinal changes in 2 patients $(2.4 \%)$. In 5 cases $(6.0 \%)$ malignancies were detected, and diabetes mellitus in 2 patients $(2.4 \%)$. A statistically significant positive correlation of SDI was established with age $(r=0,348, p=0,001)$, disease duration $(r=0,412, p<0,001)$, SLEDAl $(r=0,359, p=0,001)$, global physician's assessment $(r=0,357, p=0,001)$ and fatigue $(r=0,296, p=0,007)$, and a negative correlation with quality of life $(r=-0,386, p<0,001)$. There were no correlations of SDI with the level of anti-dsDNA, anti-nucleosome, anti-C1q antibodies, nor with serum and urine MCP1 levels.

Conclusions: Musculoskeletal, neuropsychic, and cardiovascular changes were the ones most commonly seen. Organ damage positively correlated with age and disease duration, a higher disease activity, poorer quality of life, and more severe fatigue.

References:

[1] Roberts AL, Rizzolo D. Systemic lupus erythematosus: an update on treat-totarget. JAAPA. 2015;28(9):22-8.

[2] Yee CS, Su L, Toescu V, et al. Birmingham SLE cohort: outcomes of a large inception cohort followed for up to 21 years. Rheumatology (Oxford).2015:54(5):836-43.

[3] Cervera R, Doria A, Amoura Z et al. Patterns of systemic lupus erythematosus expression in Europe. Autoimmun Rev. 2014;13(6):621-9.

Disclosure of Interest: None declared

DOI: 10.1136/annrheumdis-2017-eular.5140

\section{AB0541 CO-MORBIDITY STATUS IN SYSTEM LUPUS ERYTHEMATOSUS PATIENTS}

V. Dostanko ${ }^{1}$, V. Yagur $^{2}$, N. Dostanko ${ }^{2}$, K. Chizh ${ }^{2} .{ }^{1}$ Infomed; ${ }^{2} 2-d$ Department of Internal Medicine, BSMU, Minsk, Belarus

Background: The improved survival of patients with Systemic Lupus Erythematosus (SLE) over the past decades highlighted the problem of co-morbidity (several different chronic pathologies presence) in SLE patients because many of them reach the age when the burden of concomitant diseases could increase and become ordinary

Objectives: To evaluate the frequency of concomitant diseases and to estimate the total co-morbidity status in SLE patients.

Methods: The retrospective study of co-morbidity in SLE patients was conducted on the database of Byelorussian Republican Rheumatologic Center. It included 212 patients: 192 women and 20 men at the age of 16.1 to 68.3 (mean \pm SD: $33.2 \pm 12.3$ years) at the baseline (first visit). The diagnosis of SLE was in conformance with 1997 ACR modified classification criteria for SLE [1]. The comprehensive assessment of patient co-morbidities was performed by KaplanFeinstein co-morbidity index (KFI) [2] which includes twelve pathology categories: arterial hypertension $(\mathrm{HT})$, heart disease $(\mathrm{HD})$ presence, nervous system (ND) involvement, respiratory system (RD) pathology, vascular (VD), kidney (KD), liver (LD) gastrointestinal (GID) and musculoskeletal (MSD) diseases, other pathology (OD), malignancies and alcoholism. A co-morbidity score of 1 indicates low level of co-morbidity, 2 - moderate and 3 - high level of co-morbidity for corresponding pathology. The possible grade of co-morbidity is calculated as a sum score for all categories and varies from 0 to 36 points.

Results: KFI in SLE patients at the first visit varied from 0 to 7 points (Me: 2; $25-75 \%$ range: $0-3$ ) and had minor differences in age and sex groups (NS, Fisher's exact test). One-third of patients $(n=68)$ had no co-morbidities

One of the most common pathology was HT which was diagnosed in 39 patients $(18.4 \%, 95 \% \mathrm{Cl} 5.6-26.7 \%): 34$ women and 5 men $(\mathrm{p}=0.591$, NS, Fisher's exact test). Over the 13-year follow-up period the frequency of $\mathrm{HT}$ dramatically increased to $52.9 \%(95 \% \mathrm{Cl} 37.0-68.0 \%)$ i.e. 2.9 times vs baseline $(p<0,001)$. Prognostic odds ratios (pOR) of $\mathrm{HT}$ were $7.6(95 \% \mathrm{Cl} 3.1-18.2)$ and $3.2(1.4-7.6)$ for lupus nephritis presence and signs of glucucorticoid disease ("cushingoid"), correspondingly.

Other common co-morbidities were GID and HD. Coronary HD and congestive heart failure were revealed in $43(20.3 \%)$ patients. GID were registered in 44 (20.8\%) patients, among them $9(4.2 \%)$ patients had gastric/duodenal ulcer. VD, ND and RD were revealed in 7 (3.3\%) patients for each category, KD and LD frequency was $6(2.8 \%)$ for both pathology. MSD were registered in $8(3.8 \%)$ and OD, including different infections, anemia, diabetes etc. were registered in $39(18.4 \%)$ patients. There were no cases of malignancies or alcoholism in our patients.

Conclusions: Total co-morbidity status revealed in SLE patients at baseline varied up to the 20 percent of the maximal possible level for all age and sex groups. Arterial hypertension was one of the most common pathology which demonstrated significant and predictable growth over the 13-year follow-up period. References:

[1] Hochberg, M.C. Updating the American College of Rheumatology Revised Criteria for the classification of Systemic Lupus Erythematosus // Arthritis Rheum. 1997; 40: p.1725.

[2] Kaplan M. H., Feinstein A. R. The importance of classifying initial comorbidity in evaluating the outcome of diabetes mellitus // Journal Chronic Disease. 1974; 27: p.387-404.

Disclosure of Interest: None declared

DOI: 10.1136/annrheumdis-2017-eular.6520 